the treatment was not without side-effects, four patients complaining of considerable drowsiness or depression. Clearly a longer and larger trial is necessary, and it would be wise to wait for the results of this before the drug is prescribed extensively, for in the past many disappointments have followed initial favourable reports of treatment. A. Barbeau thought that dopa (dihydroxyphenylalanine) improved patients with Parkinsonism but that alpha methyl dopa increased the tremor. ${ }^{5}$ P. L. McGeer and L. R. Zeldowicz, also using dopa, ${ }^{6}$ found only two of ten patients improved by oral treatment. Nevertheless the work of $D$. O. Marsh and his co-workers is a neat application of the results of experiments in animals to the management of the disease in man, and their report is a careful appraisal of a drug which is pharmacologically different from those used at present. Future observations will be watched with great interest by clinicians who do their best to help these patients, and whose best is often not good enough.

\section{Rapidestimation of Barbiturates}

Many people in Great Britain are now taking barbiturates as a routine, and when an unconscious patient is admitted to hospital the problem arises whether mere presence of barbiturates in the urine indicates poisoning. The need for quantitative measurement of barbiturates has been met by laboratories in various ways. The accepted method is to examine urine or stomach contents, after various extraction procedures, in the ultra-violet spectrophotometer, though this is not yet standard equipment in many hospital laboratories in Great Britain. Moreover, though a rapid screening based on an extraction technique has been described, ${ }^{1}$ most of the older quantitative estimations are time-consuming, since the readings have to be standardized and controls have to be set up. The introduction of chromatography for detecting barbiturates was therefore a considerable advance. Of the four main types of chromatography in use gas chromatography is not generally available owing to lack of apparatus ; but conventional paper chromatography, ion-exchange paper chromatography, and thin-layer chromatography may all be used for measuring barbiturate concentrations. The last method has become popular recently,,$^{3-6}$ though it was described as early as $1949,{ }^{2}$ and I. Sunshine has reviewed its use for the diagnosis of poisoning as a whole and of barbiturate poisoning in particular. ${ }^{7}$

A screening method introduced by A. S. Curry ${ }^{8}$ uses only $2 \mathrm{ml}$. of blood, and if barbiturates are present an orange colour develops in the reaction mixture. This is a very quick qualitative test and Curry has now adapted his method to give a quantitative assay. ${ }^{9}$ This is a considerable step forward because the severity of poisoning can be estimated by this simple technique. This new procedure will undoubtedly be widely used and will be a valuable tool for clinical pathologists both for their routine and for their emergency work.

\footnotetext{
Marshall, R., Brit. med. F., 1953, 2, 379.

- Meinhard, J. E., and Hall, N. F., Analyt. Chem., 1949, 21, 185.

- Cochin, J., and Daly, J. W., Pharmacologist, 1962, 4, 171.

- Marigo, M., Arch. K'riminol., 1960, 128, 99.

- Machata, G., and Kisser, W., Arch. Toxik., 1962, 19, 327.

Eberhardt, H., and Freundt, K. J., Naunyn-Schmiedeberg's Arch. exper. Path. Pharm., 1962, 243, 310.

- Sunshine, I., Amer. F. clin. Path., 1963, 40, 576.

- Curry, A. S., Brit. med. F., 1963, 2, 1040.

- Curry, A. S., Brit. med., $1964,1,354$
}

\section{Ventricular Septal Defects}

The clinical features of ventricular septal defects of all grades of severity have been well recognized for some time. ${ }^{1-3}$ Now that lesions of this type can be repaired surgically with relative safety ${ }^{1-6}$ some controversy has arisen about the best age for operation. Thus some surgeons have advised early correction on the grounds of a high mortality from the disease in childhood, ${ }^{7}$ or because of the danger of a rising blood-pressure in the pulmonary arteries, which may increase the risks of operation or even make this impossible.

A recent report by $\mathbf{R}$. Ash ${ }^{8}$ is another of a series in recent years ${ }^{9-13}$ which has widened our knowledge of the natural history of the defect, particularly in infancy and childhood. Of special importance have been studies in which serial cardiac catheterization has been carried out, ${ }^{14}$ first in infancy and then some years later. In particular this has shown that a rising pulmonary vascular resistance in childhood is fairly uncommon. There have also been several reports ${ }^{15-17}$ of proved ventricular septal defects closing spontaneously in childhood, and surprisingly some of these defects have been large. The small defect (maladie de Roger) has no haemodynamic effect and the studies now referred to deal with the larger defect, which allows a considerable amount of blood to pass through it. This may lead to heart failure in infancy, presenting as a refusal of food, failure to grow, or repeated respiratory infections. ${ }^{10}$ Most of these infants will improve on treatment with digitalis and diuretics, though some will not survive on this medical regimen and die usually in the first three months of life. ${ }^{9}$ Constricting the pulmonary artery with a band to reduce the blood flow ${ }^{18}$ was therefore introduced to save life at this age and has proved successful, but this makes complete surgical repair later difficult. ${ }^{190}$ In some centres ${ }^{21}$ complete repair without any preliminary operation has been carried out in infancy with a low mortality.

Patients who survive infancy usually progress well in childhood, and frequently the shunt becomes smaller and hypertension in the pulmonary circulation diminishes. ${ }^{14}$ It is suggested that such improvement is due to the heart's growing faster than the defect and to the maturation of the bloodvessels in the lung. Thus in these patients there is no great urgency for operation in childhood, though even they may be remarkably improved by it, $^{4}$ and it would seem

\footnotetext{
1 Wood, P. H., Diseases of the Heart and Circulation, 1956, 2nd ed., p. 372. Eyre and Spottiswoode, London.

Nadas, A. S., Pediatric Cardiology, 1957, p. 305. Saunders, Philadelphia and London.

${ }_{3}$ Keith, J. D., Rowe, R. D., and Vlad, P., Heart Disease in Infancy and Childhood, 1958, p. 212. Macmillan, New York.

4 Cleland, W. P., et al., Brit. med. F., 1958, 2, 1369. Cooley, D. A., Garrett, H. E., and Howard, H. S., Prog. Cardiovasc. Kirklin, J. W., and Du Shane, J. W., Amer. F. Cardiol., 1963, 12, 75. Drew, C. E., Brit. med. F., 1963, 2, 305.

- Ash, R., F. Pediat., 1964, 64, 45.

- Zacharioudakis, S. C., Terplan, K., and Lambert, E. C., Circulation,

10 Maxwell, G. M., Rowe, G. G., and Crumpton, C. W., Arch. Dis. Childh., 1958, 33, 67.

${ }^{11}$ Fyler, D. C., Rudolph, A. M., Wittenborg, M. H., and Nadas, A. S., Circulation, 1958, 18, 833.

12 Brotmacher, L., and Campbell, M., Brit. Heart f., 1958, 20, 97.

is Morgan, B. C., Griffiths, S. P., and Blumenthal, S., Pediatrics, 1960 $25,54$.

14 Arcilla, R. A., et al., Circulation, 1963, 28, 560.

15 Evans, J. R., Rowe, R. D., and Keith, J. D., ibid., 1960, 22, 1044.

16 Nadas, A. S., Scott, L. P., Hauck, A. J., and Rudolph, A. M., New Engl. F. Med., 1961, 264, 309.

17 Wade, G., and Wright, J. P., Lancet, 1963, 1, 737.

18 Muller, W. H., and Dammann, J. F., Surg. Gynec. Obstet., 1952, 95, 213 .

19 Morrow, A. G., and Braunwald, N. S., Circulation, 1961, 24, 34

20 Albert, H. M., et al., ibid., 1961, 23, 16.

21 Kirklin, J. W., and Du Shane, J. W., Pediatrics, 1961, 27, 961.

22 Wood, P., Brit. med. F., 1958, 2, 701.
} 
unwarranted to deny them the benefits of operation for too long. Spontaneous closure of defects usually occurs before the age of 5 years. ${ }^{17}$

A small group of patients develop progressive pulmonary hypertension. These subjects have usually had a high pulmonary vascular resistance from birth and sooner or later the flow of blood through the shunt becomes reversed-the so-called "Eisenmenger complex." The signs of the latter are those of increasing right ventricular hypertrophy; signs of left ventricular hypertrophy diminish, as does the characteristic murmur. Operating on these patients is much more risky than in those with uncomplicated defects, though careful studies by cardiac catheterization show that surgical correction is still possible in many. If the pulmonary artery pressure cannot be lowered by operation, surgery is probably contraindicated. Moreover, the expectation of life of a patient with Eisenmenger's complex may be considerable ${ }^{22}$ and some patients who cannot be operated on will live well into adult life.

Most patients with ventricular septal defects who survive childhood progress well until about the age of 15-20 years, after which they tend to deteriorate, and few live longer than $40 .{ }^{12}$ Death is due to heart failure produced by the large volume of the shunt, or from a rising pulmonary vascular resistance. A few chlldren show a reduction in the volume of the shunt owing to the development of hypertrophic stenosis of the infundibulum of the aortic valve ; this may eventually cause reversal of the shunt. All these patients should be treated by operation similar to that used to correct Fallot's tetralogy. It should also be remembered that other congenital cardiac defects may be present in any patient in whom surgery is contemplated..$^{4-6}$

Usually, therefore; patients with large ventricular septal defects should undergo surgical repair in infancy only when heart failure is intractable ; similarly in early childhood operation should be undertaken only in those patients showing a rising pulmonary vascular resistance or in those who fail to thrive. In the remainder operative correction should certainly be performed before the early teens, but the exact time will depend on symptoms, social circumstances, and the particular experience of the local surgical team.

\section{A Fungus in Osteoarthritis}

In certain river valleys in the Transbaikal area of Siberia a curious form of joint disease has been endemic for over 100 years. N. I. Kashin ${ }^{1}$ reported that Cossacks settled in this area developed a deforming arthritis and that goitre was also very prevalent there. A more detailed account of this disease with its epidemiology was published by E. B. Beck, ${ }^{2}$ and since that time it has been known as Kashin-Beck's disease.

The disease is characterized by episodes of pain and swelling in many joints followed by the development of premature generalized osteoarthritis. Patients born in the endemic area may develop epiphysial necrosis in childhood resulting in severe deformities, but people moving into the endemic area in adult life develop only a modified form of the disease. No familial aggregation has been reported, but

\footnotetext{
Kashin, N. I., Moscow Medical Newspaper, 1861, pp. 5 and 39.

2 Beck, E. B., Russian Physician, 1906, 3, 74.

Kotrechov, P. F., Urovskaya Bolezin, 1953. Moscow.

S Nesterov, A. I., Arthr. and Rheum., 1964, 7, 29.
}

temporal variations in incidence have, incidence being highest after exceptionally wet harvests. This condition has therefore all the characteristics of a disease due to something in the environment. Recent clinical observations and animal experiments suggest that it is caused by ingesting the locally grown cereals, which are often heavily contaminated with moulds, notably Fusaria sporotrichiella, because of the unusual climate in this region, and the disease is said to be prevented by importing grain from outside the endemic area. The pathogenesis of the joint lesions has not been fully worked out, but the current hypothesis is that some toxic material is produced in the Fusaria-infested grain. P. F. Kotrechov ${ }^{3}$ published a good review of the subject, and A. I. Nesterov has recently given an authoritative account in the Englisb language."

If toxic Fusaria moulds can produce severe endemic osteoarthritis in Siberia it is possible that they might contribute to the causation of the disease in other parts of the world. There are, however, many strains of Fusaria sporotrichiella and only some of them may be toxic. ${ }^{5}$ The toxic strains probably flourish only in the Urov district of Siberia, so that this question may be of little importance elsewhere. But the discovery of a dietetic cause of generalized osteoarthritis raises interesting theoretical possibilities.

\section{Isolated Growth-hormone Deficiency}

Dwarfism due to deficiency of pituitary growth hormone is uncommon. When it is due to a gross lesion of the pituitary gland or hypothalamus, such as craniopharyngioma or HandSchüller-Christian disease, diagnosis is not difficult. But without such a lesion the diagnosis of pituitary dwarfism often remains presumptive until the child reaches puberty, when failure of development is convincing evidence of the absence of pituitary gonadotrophic hormones as well as of growth hormone. Before then hypoglycaemic attacks and increased sensitivity to insulin are valuable pointers to the diagnosis. In a few patients there are also signs of impaired activity of the thyroid gland and the adrenal cortex, resulting from decreased secretion of thyroid-stimulating hormone and corticotrophin.

The possibility of deficiency of pituitary growth hormone alone has often been entertained, but it has never been firmly established in man. Recently, however, H. L. Nadler and his colleagues $^{1}$ have provided evidence in favour of its existence. Their patient, a 13-month-old boy, was severely dwarfed, and the growth-hormone-like activity of his serum xas found to be deficient. Studies of carbohydrate metabolism showed a low level of sugar in the blood both before and after meals, as well as hypoglycaemia after tolbutamide and leucine. The functions of the thyroid and the adrenal cortex were, however, normal. There was a remarkable response to treatment with human growth hormone: carbohydrate metabolism promptly returned to normal and during the three months' course of treatment the child grew 7 in. (18 cm.), compared with only 1 in. $(2.5 \mathrm{~cm}$.) in the previous 13 months. Shortly after treatment was stopped growth ceased for at least six months.

The authors make out an impressive case in support of the concept of an isolated deficiency of growth hormone. How-

\footnotetext{
1 Nadler, H. L., Neumann, L. L., and Gershberg, H., f. Pediat., 1963,
63, 977.
} 